\title{
Carboxyhaemoglobin dissociation in the cadaver following attempted resuscitation
}

\author{
H. M. RICE \\ From the Department of Pathology, General Hospital, University of Nottingham
}

SYNOPSIS A series of 300 cases of fatal carbon-monoxide poisoning showed wide variations in carboxyhaemoglobin saturation. Levels below $50 \%$ in 24 subjects under the age of 70 were probably falsely low following attempted resuscitation on the way to hospital. Artificial respiration, especially with oxygen-rich gas, causes dissociation of carboxyhaemoglobin in the lungs of the cadaver while movement of blood into and out of the lungs, with mixing, lowers the saturation levels in the neighbouring large veins. In four cases subclavian blood showed saturation levels much lower than blood from sites further from the lungs. Blood should be taken from the femoral vein to get true readings.

Carbon-monoxide poisoning used to be a common cause of death, both accidental and suicidal, before the conversion of domestic supplies from coal gas to natural gas. Though now relatively rare, fatal cases still occur from such causes as house-fires, bathroom geysers with faults in flues or maintenance, carexhaust fumes, and the use of oil-heaters in inadequately ventilated rooms, particularly in cold weather and by immigrants from warmer countries. The wide variations in carboxyhaemoglobin saturation levels found in fatal cases have puzzled pathologists for many years. This paper offers explanations for some of them.

From the time of Haldane's classical experiments the lethal concentration of carboxyhaemoglobin in the blood has been accepted as $70 \%$ saturation. With the supercession of reversion spectroscopy by more accurate methods of analysis the determination of saturation levels on all fatal cases became general, and the variations found could be attributed to causes other than technical inaccuracy. The standard textbooks of forensic medicine are in broad agreement about fatal concentrations. Glaister (1973) and Taylor (1965) give $60 \%$ saturation as the lethal minimum. Taylor goes on to say that middle-aged persons normally succumb at $50-60 \%$, while healthy young adults often reach $75-80 \%$ saturation. Elderly and infirm persons, particularly those suffering from cardiac and respiratory diseases, may die with concentrations as low as $30 \%$. Curry (1969) says that

Received for publication 26 June 1975. death may occur at saturations down to $40 \%$, if low concentrations of carbon-monoxide are breathed for a long time. Many pathologists, however, have experience of fatalities which, from circumstantial evidence, sometimes supported by suicide notes, can only have been cases of carbon-monoxide poisoning but which showed saturation levels considerably below the lethal minimum quoted, even down to $40 \%$, in apparently healthy subjects and when the evidence did not suggest the prolonged breathing of gas at low concentrations. On the other hand, I have known recovery, without evident permanent disability, from saturations as high as $\mathbf{5 0 \%}$ (two cases), said by Taylor to be certain to cause irreversible damage to the central nervous system.

Figures 1 and 2 show the carboxyhaemoglobin saturation levels in 300 consecutive fatal cases, 184 male and 116 female. Lines have been drawn at $50 \%$ saturation, Taylor's lower limit for the middle-aged, and at 70 years of age, chosen arbitrarily to define elderly. Results are summarized according to sex, age, and carboxyhaemoglobin saturation, in the table. The nine values below $40 \%$ saturation were all in persons aged 80 or more and may therefore be ignored on grounds of age. Within the defined limits (50\% saturation and 70 years) there were, however, 24 cases, 17 male and seven female, with saturation levels from $40 \%$ to $49 \%$, who cannot be classed as elderly and who showed no postmortem evidence of infirmity. Why these levels should have proved fatal when recovery is possible from $50 \%$ saturation was a puzzle, particularly as they inclu- 


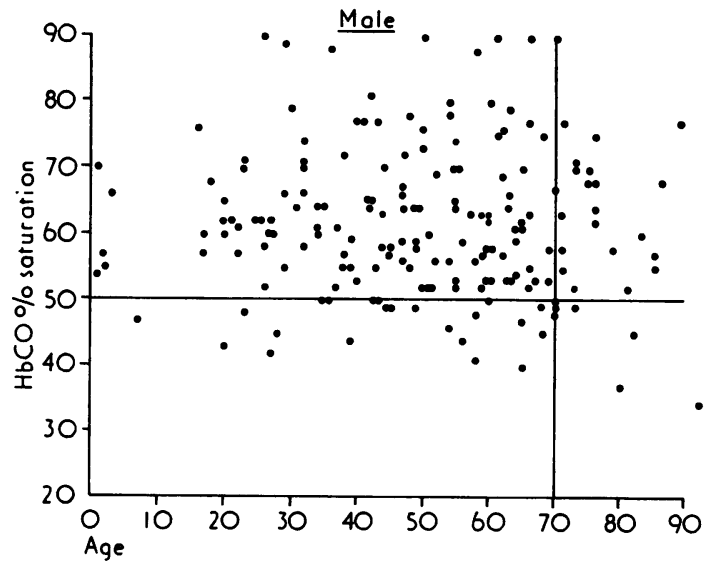

Fig 1 Carboxyhaemoglobin saturation plotted against age for 184 male cases; $15.8 \%$ are aged 70 or over: 17 cases under 70 with saturation levels below $50 \%$.

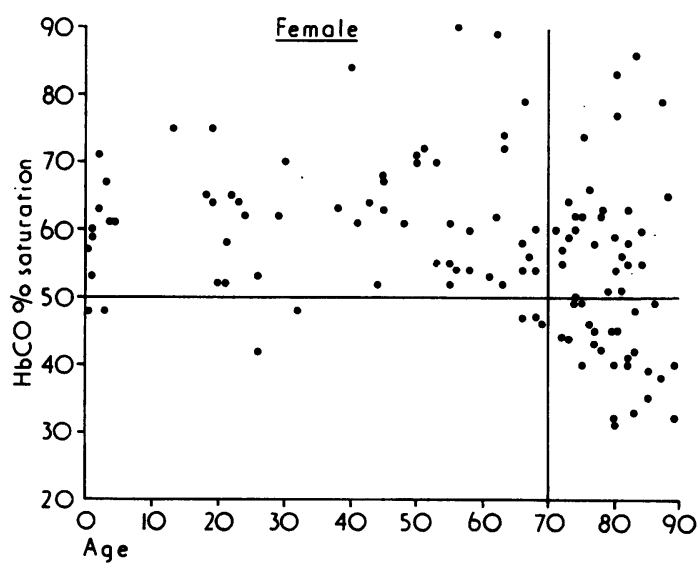

Fig 2 Carboxyhaemoglobin saturation plotted against age for 116 female cases; $46.6 \%$ are over the age of 70 . 7 cases under 70 with less than $50 \%$ saturation.

ded apparently healthy young adults in their twenties and thirties.

I believe that the saturation levels were probably falsely low, due to dissociation of carboxyhaemoglobin after death when artificial respiration had been used in attempts at resuscitation.

Since blood with a high concentration of carboxyhaemoglobin does not coagulate, vigorous attempts at artificial respiration 'cause movement of blood into and out of the lungs which may amount to actual circulation if sufficient to activate the valvular system. This is more likely to occur when the

\begin{tabular}{|c|c|c|c|c|c|c|c|c|}
\hline \multirow[t]{3}{*}{ Sex } & \multirow{3}{*}{$\begin{array}{l}\text { Total } \\
\text { Cases }\end{array}$} & \multirow{3}{*}{ Age } & \multirow{2}{*}{\multicolumn{2}{|c|}{ Cases }} & \multicolumn{4}{|c|}{ HbCO Saturation $\%$} \\
\hline & & & & & \multicolumn{2}{|l|}{$50+$} & \multicolumn{2}{|c|}{ Below 50} \\
\hline & & & No. & $\begin{array}{l}\% \text { of } \\
\text { total }\end{array}$ & No. & $\%$ & No. & $\%$ \\
\hline \multirow[t]{2}{*}{ Male } & \multirow[t]{2}{*}{184} & \multirow{2}{*}{$\begin{array}{l}70+ \\
\text { Below } \\
70\end{array}$} & 29 & $15 \cdot 8$ & 23 & 79 & 6 & 21 \\
\hline & & & 155 & $84 \cdot 2$ & 138 & 89 & 17 & 11 \\
\hline \multirow[t]{2}{*}{ Female } & \multirow[t]{2}{*}{116} & \multirow{2}{*}{$\begin{array}{l}70+ \\
\text { Below } \\
70\end{array}$} & 54 & $46 \cdot 6$ & 29 & $53 \cdot 8$ & 25 & $46 \cdot 2$ \\
\hline & & & 62 & $53 \cdot 4$ & 55 & $88 \cdot 7$ & 7 & $11 \cdot 3$ \\
\hline
\end{tabular}

thorax is highly elastic, in young subjects. Gaseous exchange, with dissociation of carboxyhaemoglobin, occurs and is facilitated by a high oxygen content of the respired gas, as when breathing apparatus is used. The degree of gaseous exchange depends on the vigour and duration of the artificial respiration but will always be greatest in blood from the lungs themselves, the heart, and the great vessels closest to them. It is, therefore, important that carboxyhaemoglobin saturation levels be determined on blood from a more distant site, preferably the femoral vein in the thigh, where diffusion of gases and mixture of highly saturated and partly dissociated blood can have little, if any, effect. My practice has always been to take blood samples from the subclavian veins, to avoid the possibility of contamination. Four cases illustrate the fallibility of such sampling.

\section{Case Reports}

CASE 1

A child, 14 months old, was found apparently dead in a smouldering room-fire. One leg was extensively burnt. Ambulance personnel performed artificial respiration with pure oxygen on the way to hospital. There an intravenous saline drip was put up and artificial respiration was continued for about an hour before death was pronounced.

The postmortem appearances were typical of carbon-monoxide poisoning. Hypostasis was bright pink. The burns were postmortem in character (confirmed histologically). The trachea and bronchi contained mucus streaked with the oily, sooty deposit typical of smoke from smouldering furniture. There was no organic abnormality.

Subclavian blood showed only $15 \%$ saturation with carboxyhaemoglobin. This was obviously a falsely low level, so blood was taken from the femoral vein of the uninfused leg and showed $31 \%$ saturation. It was concluded that the intravenous infusion had assisted the circulation and mixing of 
the blood, while resuscitative efforts were continued so long that virtually all blood in the larger vessels would have been affected.

\section{CASE 2}

A man of 57 was found dead on the floor with his head on a cushion and covered by a dressing gown, under which led the disconnected coal gas supply pipe. He was already cold, but artificial respiration was performed on the way to hospital, where he was pronounced dead.

The postmortem appearances were again characteristic. No organic abnormality was found.

Subclavian blood showed only $32 \%$ saturation. The level in a femoral sample was $52 \%$.

\section{CASE 3}

The body of a woman aged 43 was recovered from a burning room. Fire service personnel attempted resuscitation, using artificial respiration and pure oxygen.

There were extensive second-degree burns and the postmortem appearances were again characteristic of death in a conflagration. There was no organic abnormality.

Carboxyhaemoglobin saturation levels were: subclavian vein $42 \%$, common iliac vein $45 \%$, femoral vein $59 \%$.

\section{CASE 4}

One other case, antedating the other three, is worth mentioning, although femoral blood was not sampled. Another infant aged 5 months died in a room-fire. Postmortem appearances were characteristic of carbon-monoxide poisoning. The viscera had been removed in one piece (standard practice with infants) so, since the subclavian sample was scanty, blood draining into the body cavity was also taken. It showed $48 \%$ saturation, against $34 \%$ in the subclavian blood. Again, artificial respiration had been performed.

Enquiries from the Ambulance Service revealed that, in Nottingham and Nottinghamshire, it has been standard practice for at least six years for all ambulance crews to perform artificial respiration, using breathing apparatus and either pure oxygen or Entonox mixture (equal parts of oxygen and nitrous oxide), on all persons found dead, unless decomposition or the nature of injuries make it obviously inappropriate. Previously, not all ambulances had been fully equipped, though the Minute man apparatus had been widely available for over 20 years. Artificial respiration, with oxygen if available, had been given at the discretion of the ambulance crew.

I think this is the explanation for the variations in our saturation levels, from $90 \%$ down to $40 \%$. The method of analysis, using the reduction of palladium chloride in a Conway unit, is accurate to within $5 \%$ in skilled hands. There is no reason to suppose that artificial respiration was not employed in most, if not all, the cases with low saturation levels, since it was nearly always given before it became mandatory. In some cases it would have been applied more vigorously and for longer than in others, so that the degree of dissociation of carboxyhaemoglobin would have varied. As blood samples were routinely taken from the subclavian veins many of our readings may well have been falsely low. It may be significant that in all the 10 cases in this series showing decomposition, when artificial respiration would not have been attempted, the lowest saturation recorded was $57 \%$.

The part played by diffusion and the extraordinarily high levels, up to $90 \%$ in some cases, remain subjects for speculation. It appears possible that additional carboxyhaemoglobin saturation can occur post mortem if the lungs are full of carbon monoxide, and if artificial respiration is not carried out vigorously and for long enough to wash the gas out of the lungs and so enable dissociation of carboxyhaemoglobin to begin.

As hypostasis remains bright pink in the cases with low saturation levels, it is desirable to sample peripheral capillary blood, which remains unaffected by artificial respiration.

It would be interesting to see if complete dissociation of carboxyhaemoglobin, theoretically possible, could be achieved post mortem in an experimental animal by prolonged artificial respiration.

I thank HM Coroner for the City of Nottingham for permission to publish, and am most grateful to $\mathrm{Dr}$ G. F. M. Hall for allowing me to include some of his cases, and to $\mathrm{Mr}$ A. D. Bridge, BSc, and the late $\mathrm{Mr}$ C. E. Vernon, MSc, ARIC, for the analyses.

\section{References}

Curry, A. S. (1969). Poison Detection in Human Organs, 2nd ed. Thomas, Springfield, Illinois.

Glaister, J. (1973). Medical Jurisprudence and Toxicology, 13th ed., edited by E. Rentoul and H. Smith. Churchill Livingstone, Edinburgh and London.

Taylor, A. S. (1965). Principles and Practice of Medical Jurisprudence, 12th ed., edited by K. Simpson. Churchill, London. 